\title{
Genetic diversity of Alternaria alternata Isolates Causing Potato Brown Leaf Spot, Using ISSR Markers in Iran
}

Shima Bagherabadi, Doustmorad Zafari* and Mohammad Javad Soleimani

Department of Plant Protection, College of Agriculture, University of Bu Ali Sina, Hamedan, Iran

\begin{abstract}
Sampling was carried out from different fields in Hamedan province, Iran during the years 2012 and 2013. Among the 300 obtained isolates of Alternaria spp. after morphological identification, it was revealed that $A$. alternata isolates from potato had the highest frequency distribution. Due to the abundance of this species in this region which is considered as a major potato producing province in the country, genetic diversity of its isolates were assessed using ISSR markers. Among $A$. alternata isolates, 11 isolates screneded from nine different regions on four potato cultivars were selected. A total of 15 ISSR primers of UBC group were used to investigate the genetic diversity of these isolates. Out of 15 primers used in this study, 5 primers had favorable results and produced a significant number of bands. Based on the results of cluster analysis using the Jaccard's coefficient, isolates were divided into two main groups and there was some correlation between the grouping of isolates regarding their geographic location, pathogenicity and potato cultivars.
\end{abstract}

Keywords: Alternaria alternate; Cluster analysis; Diversity analysis; ISSR markers; Potato

\section{Introduction}

Alternaria alternata (Fr.) Keissler is common saprobe found on many plants and other substrate worldwide [1-3] and can cause damage to many plants in different agro ecosystems, including potato brown leaf spot disease. It is mainly found in the soil or on decomposing plant tissues [4]. This species is also an opportunistic pathogen affecting many cultivated plants in the field and during post-harvest storage of fruit and vegetables. This fungus attacks plants including cereals, ornamental plants, magnolia, oilseeds, vegetables such as cauliflower, broccoli, eggplant, pepper, carrot, potato, tomato, bean and fruits such as citrus, apple, strawberry and peach and in some cases, is known as post-harvest pathogens [5]. In recent years, molecular markers have been used for practical studies of many organisms. In a way, that exploring the various types of molecular markers has made major progresses in genetic studies [6]. DNA is the essence of genetic differences between two specified organism and DNA fingerprinting is now one of the methods for identification of biological organisms. DNA polymorphism is the base of many genetic studies [1]. Genetic diversity is the base of evolution of species and populations [7]. The ability of a population to adapt to different environmental conditions is dependent on the level of genetic diversity [8]. Populations with higher genetic diversity are stable against changes in environmental conditions. Therefore, the first step for managing a plant pathogen is to investigate the diversity. One of the reasons for lack of success in the management of plant diseases is due to lack of information about the structure of the pathogen populations; therefore enhancing knowledge in this area will certainly be helpful in adopting effective methods of managing a pathogen. Therefore being aware of the genetic diversity of populations and the structure of populations within a species, not only checks the evolutionary processes and mechanism of that, but also provides useful information about biological conservations [9].

There are several methods for evaluating genetic diversity. The choice of molecular markers depends on their high reproducibility, simplicity of method, low cost and high reliability. In 1994, a new type of molecular markers briefly known as ISSR was introduced by Zitkovich et al. and quickly was used in different fields. These markers have high similarity to RAPD markers and are widely dispersed throughout the genome [10]. ISSR is a multilocus marker that in addition to these features does not have the restrictions of other markers such as low reproducibility in RAPD, high costs and complexity in AFLP [11]. ISSR being able to create polymorphism patterns among near-organisms and their reproducibility caused to be known as informative markers with a wide range of applications including the study of genetic diversity [12]. Recent studies show the extremely diverse nature of these markers and their potential to study the different levels of population [2]. Although for some Alternaria species Lewia is known as sexual stage but the sexual stage of $A$. alternata is unknown $[3,13]$. These species are likely haploid which reproduce asexually in vegetative phase and is expected to have a low genetic diversity. Guo et al. [14] used 20 ISSR primers to study genetic diversity of 112 isolates of endophytic Alternaria alternata isolated from pine in China. They found out tha of these, only two primers showed high levels genetic diversity of this species in pine. Their results showed no correlation between the fungal genotype and host age and endophytes of $A$. alternata had great potential for development and maintenance of genetic diversity. Zhong-hui et al. [15] also studied genetic variation in eight isolates of A. alternata at five region of China on Tobacco using ISSR markers. Kale et al. [16] studied genetic diversity of 20 isolates of A. alternata on linseed at 14 districts of India using nine ISSR primers. Their research results showed that there was a high genetic diversity among these 20 isolates and no correlation between genetic diversity, geographic region, and intensity of pathogenicity.

Hamedan province in Iran, through having good and adapted

*Corresponding author: Doustmorad Zafari, Department of Plant Protection, College of Agriculture, University of $\mathrm{Bu}$ Ali Sina, Hamedan, Iran, Tel: +989183137285; Fax: +988134424190; E-mail: Zafari_d@yahoo.com

Received June 15, 2015; Accepted July 04, 2015; Published July 10, 2015

Citation: Bagherabadi S, Zafari D, Soleimani MJ (2015) Genetic diversity of Alternaria alternata Isolates Causing Potato Brown Leaf Spot, Using ISSR Markers in Iran. J Plant Pathol Microb 6: 286. doi:10.4172/2157-7471.1000286

Copyright: $\odot 2015$ Bagherabadi S, et al. This is an open-access article distributed under the terms of the Creative Commons Attribution License, which permits unrestricted use, distribution, and reproduction in any medium, provided the original author and source are credited. 
weather for the cultivation of potato has dedicated a large percentage of potato production in the country to itself, With cultivated area equal to 25,000 hectares and annual production of 900 thousand tons potato tubers has gained an special position in production of potato in the country.

Since A. alternata is one of the most important pathogens causing potato brown leaf spot in this region, the aim of this study was determined to investigate the genetic diversity of isolates of this species on potato using ISSR markers in Hamedan province, Iran.

\section{Materials and Methods}

\section{Sampling, isolation and identification}

Sampling was done during the spring, summer and autumn of 2012 and 2013 from potato fields, in different locations of Hamedan province, Iran. The collected samples were placed separately in paper bags and plant names, place and date of sample collection was recorded. In order to conduct further studies plant tissues were transported to the laboratory and stored in a refrigerator at $4^{\circ} \mathrm{C}$. Plant organs with suspected symptoms of contamination were washed under running water for 5 minutes. Sections possess symptoms were cut from healthy sections and segmented into parts of 0.5 to $1 \mathrm{~cm}$. These segments were surface sterilized with 10 percent sodium hypochlorite for 2 minutes and immediately were washed twice with sterile distilled water. The pieces on the dewatering filter paper were transferred to the petri dishes containing potato dextrose agar (PDA) medium. Petri dishes were kept in an incubator at $23-25^{\circ} \mathrm{C}$. Five to seven days after incubation, isolates were purified using single spore method and then were transferred to the tubes containing potato carrot agar (PCA) medium for storage and subsequent studies. Microscopic identification at the genus level was achieved using Lica microscope according to the imperfect fungi key [17].

\section{Evaluation of morphological features}

To study the morphological characteristics of purified isolates at the species levels, subcultures were transferred to the petri dishes containing PCA medium. These petri dishes were kept at 23 to $25^{\circ} \mathrm{C}$ under fluorescent light with light cycle of 8 hours light and 16 hours dark and were studied after five to seven days. For white light, two 40 W white fluorescent lamps were used at the distance of $40 \mathrm{~cm}$ from the surface of petri dishes. Microscopic identification was achieved using Lica microscope according to descripion of Alternaria species [18] After morphological identifications, Alternaria isolates with higher frequency were selected for further studies such as study of thier pathogenicity and genetic diversiy.

\section{Pathogenicity test}

To conduct the pathogenicity test, healthy potato tubers were cultured in sterilized pots containing pasteurized soil. Potato seedlings with 5-6 leaves, were sprayed separately with A. alternata spore suspension $\left(10^{6}\right.$ spores per $\left.\mathrm{ml}\right)$ of each isolate. $48 \mathrm{~h}$ before pathogen inoculation, plants were covered with plastic bags to keep the relative humidity at $100 \%$. To avoid air trapped small holes was created at the top of the bags. After pathogen inoculation, the plants covered for 48 hours with plastic bags and were kept in greenhouse conditions with 14 hours light and 10 hours of darkness.

\section{Molecular studies}

Among 165 obtained isolates of A. Alternata from potato in differrent reagions of Hamedan province, screening was achived according to the main reagiones of potato production in this province and kind of potato cultivatrs that isolates were isolated from those, therefore due to the great similarity among isolates from each reagion and considering to potato cultivare 11 isolates as representative were screened for study of gentics diversity.

\section{DNA extraction}

Mycelia of A. alternata isolates grown in potato dextrose broth (PDB) medium were collected, washed and were kept at $-20^{\circ} \mathrm{c}$. DNA was extracted using modified method of Sharma et al. [19]. Frozen mycelia were poured in a porcelain mortar which was pre-chilled in the freezer and were powdered in liquid nitrogen. $200 \mathrm{mg}$ of powdered mycelia were transferred to each $1.5 \mathrm{ml}$ tubes and $750 \mu \mathrm{l}$ of extracted buffer stored in $60^{\circ} \mathrm{C}(2 \%$ PVP-40, pH 8.0 EDTA $20 \mathrm{mM}$, CTAB 5\% (W/V) Tris- $\mathrm{HCl}$ pH 8.0100 mM, NaCl 1.4 M, 2.0\% mercaptoethanol) was added to each sample, mixed and for 35 minutes was kept in $60^{\circ} \mathrm{C}$ hot water bath and at this time the contents of the tubes were shaken gently several times. Equivalent to the volume of the tube, the mixture of chloroform - isoamyl alcohol (1:24) was added to each tube containing the sample and was mixed gently for one minute.

The mixture was centrifuged for $15 \mathrm{~min}$ at $7,000 \mathrm{rpm}$, then supernatant was taken and poured into a new sterile tube. Sodium acetate of $3 \mathrm{M}, 5.2 \mathrm{PH}$ and 0.6 volume of cold isopropanol solution was added to one to thirty of volume and the solution in the tubes was gently mixed several times, at this stage, the DNA strands were formed which were easily visible. The tubes containing DNA strands were centrifuged for $10 \mathrm{~min}$ at $7000 \mathrm{rpm}$ at $4^{\circ} \mathrm{C}$ and the supernatant was emptied gently so that the DNA remained intact inside the tube. Then $500 \mathrm{ml} \mathrm{70 \%} \mathrm{ethanol}$ was added to the tubes containing DNA, and centrifuged at $13,000 \mathrm{rpm}$ at $4^{\circ} \mathrm{C}$ for $5 \mathrm{~min}$. The upper phase was discarded and tubes in the air upside down were placed on absorbent paper so that the deposition driedand finally $50 \mu \mathrm{l}$ of sterile double- distilled water was added to each tube. The samples were stored overnight in the refrigerator until the mass of DNA distilled in water. To detect the extracted DNA, 1.2\% Agarose gel in TBE buffer was used and then $5 \mu$ of DNA with double amount of loading buffer was mixed and electrophorzed at a constant voltage of 80 volts for 1.5 hours. Quantity and quality of extracted DNA was determined by spectrophotometry and agarose gel electrophoresis.

\section{Regulation of polymerase chain reaction (PCR)}

To confirm the morphological identification, one of the isolates was selected as representative for molecular analysis and protein encoding gene of Glyceraldehyde 3-phosphate dehydrogenase (GAPDH) was amplyfied and sequenced. To assess the genetic diversity of isolates of this species, ISSR marker was selected and 15 UBC primers were used for conducting the test in polymerase chain reaction. The names and $g p d_{1}, g p d_{2}$ sequences of primers and specific UBC primer are listed in Table 1 .

At the time of conducting tests, to prevent the time error, taking very small amounts of materials and to practice more easily and quickly, master mix of PCR reactions was prepared as shown in Table 2. Master mix includes all materials needed for the PCR reaction except DNA sample and primer.

Firstly, $2 \mu$ of DNA of each sample was poured into PCR specific micro-tubes, then $2 \mu \mathrm{l}$ primers (with concentration of $10 \mathrm{pmol} /$ $\mu \mathrm{l})$ was added and kept in the refrigerator. Immediately, $21 \mu \mathrm{l}$ of the master mix was added to the each micro-tube containing DNA and primer. Thermocycler device of Techne model TC-512 was used 


\begin{tabular}{|c|c|}
\hline The name of primer & Sequence \\
\hline UBC 807 & 5'-AGAGAGAGAGAGAGAGT-3' \\
\hline UBC 808 & 5'AGAGAGAGAGAGAGAGC-3' \\
\hline UBC 809 & 5'-AGAGAGAGAGAGAGAGG-3' \\
\hline UBC 818 & 5'-CACACACACACACACAG-3' \\
\hline UBC 822 & 5-ТСТСТСТСТСТСТСТСА-3' \\
\hline UBC 834 & 5'-AGAGAGAGAGAGAGAGCT-3' \\
\hline UBC 835 & 5-AGAGAGAGAGAGAGAGCC-3' \\
\hline UBC 840 & 5'-GAGAGAGAGAGAGAGATT-3' \\
\hline UBC 841 & 5'-GAGAGAGAGAGAGAGACC-3' \\
\hline UBC 842 & 5'-GAGAGAGAGAGAGAGATG-3' \\
\hline UBC 846 & 5'-CACACACACACACACAAT-3' \\
\hline UBC 849 & 5'-GTGTGTGTGTGTGTGTCA-3' \\
\hline UBC 850 & 5'-GTGTGTGTGTGTGTGTCA-3' \\
\hline UBC 856 & 5'-ACACACACACACACACCA-3' \\
\hline gpd1 & 5'CAACGGCTTCGGTCGCATTG-3' \\
\hline gpd2 & 5-GCCAAGCAGTTGGTTGTGC-3' \\
\hline
\end{tabular}

Table 1: Names and sequences of primers used in this study.

\begin{tabular}{|c|c|c|c|}
\hline $\begin{array}{c}\text { Per one } \\
\text { reaction }\end{array}$ & $\begin{array}{c}\text { Final } \\
\text { concentration }\end{array}$ & $\begin{array}{c}\text { Basal } \\
\text { concentration }\end{array}$ & Material \\
\hline $15.2 \mu \mathrm{l}$ & - & - & Sterile double distilled water \\
\hline $2.5 \mu \mathrm{l}$ & $1 \mathrm{X}$ & $10 \mathrm{X}$ & PCR buffer \\
\hline $1.6 \mu \mathrm{l}$ & $3.2 \mathrm{Mm}$ & $50 \mathrm{Mm}$ & $\mathrm{MgCl}_{2}$ \\
\hline $1.5 \mu \mathrm{l}$ & $0.6 \mathrm{Mm}$ & $10 \mathrm{Mm}$ & dNTPS \\
\hline $0.2 \mu \mathrm{l}$ & $1 \mathrm{Unit}$ & $5 \mathrm{Unit} / \mu \mathrm{l}$ & Taq DNA polymerase enzyme \\
\hline $21 \mu \mathrm{l}$ & - & - & *Total volume of master mix \\
\hline
\end{tabular}

Table 2: Ingredients and amounts for the preparation of master mix used in the $\mathrm{PCR}$ reaction. *Final volume of PCR reaction: $(2 \mu \mathrm{l} \mathrm{DNA}+2 \mu \mathrm{l}$ Primer+21 $\mu \mathrm{l}$ master $\operatorname{mix}=25 \mu$.

\begin{tabular}{|c|c|c|c|}
\hline Number of cycles & Conducted Steps & Time & Temperature $\left({ }^{\circ} \mathrm{C}\right)$ \\
\hline \multirow{3}{*}{35 Cycle } & Initial denaturation & $5 \mathrm{~min}$ & 94 \\
\hline \multirow{3}{*}{35 cycles } & Denaturation & $1 \mathrm{~min}$ & 94 \\
\cline { 2 - 4 } & Annealing & 75 second & $\begin{array}{c}\text { Depending on the type of } \\
\text { primer used }\end{array}$ \\
\cline { 2 - 4 } 1 cycle & Extension & $2 \mathrm{~min}$ & 72 \\
\hline
\end{tabular}

Table 3: Time and temperature required for conducting different stages of PCR for primers $\mathrm{gpd}_{1}, \mathrm{gpd}_{2}$ and specific UBC primers.

for amplification. According to the program given to the machine, polymerase chain reaction (PCR) was conducted using primers based on the conditions shown in Table 3.

\section{Electrophoresis of PCR products}

For electrophoresis of each sample, $5 \mu \mathrm{l}$ of the initial PCR product was removed and after mixing with $2 \mu \mathrm{l}$ of loading buffer, electrophorzed on the $1.2 \%$ agarose gel in TBE buffer with constant voltage of $80 \mathrm{kV}$ for 2.5 hours. The samples were run on a solution of ethidium bromide for 30 minutes $(5.0 \mathrm{mg}$ per $\mu \mathrm{l})$. After washing the gel with distilled water, the gel was subjected to image analysis with a gel document device (DIGI.DOC H101 model).

\section{Sequenced regions of $g p d$}

To determine the DNA sequence of a representative isolate, regions of $g p d$ were amplified and sequenced. Obtained sequences were blasted with the sequences of these regions related to the isolates of this species in the GenBank.

\section{Analysis of data obtained from UBC primers}

The resulting band patterns of each isolate were scored for the presence or absence of amplified products. Cluster analysis of the data was done using UPGMA, by the use of Jaccard's similarity coefficient in the NTSYS-PC software (version 2) and a dendrogram was constructed for each primers and total primers. Decomposition to main coordinates on similarity matrix was obtained through Jaccard's similarity coefficient. To determine the optimal number of clusters in which the highest distinction between the groups is achieved, analysis of molecular variance (AMOVA) was used.

\section{Results and Discussion}

In this study, 300 isolates of Alternaria were obtained from different hosts and regions in Hamedan province and were identified at species level, based on morphological characteristics. Among identified isolates, 165 isolates were belonged to the A. alternata species isolated from potato crop (Table 4). Since isolates of A. alternata from potato were the most frequent spcies, genetic diversity of these isolates was studied by using ISSR marker. Among collected isolates from potato crops in this study, 11 isolates were selected from nine different regions and four different potato cultivars in Hamedan province (Table 5).

\begin{tabular}{|c|c|c|c|}
\hline Item & Name of isolates & Host & $\begin{array}{l}\text { Number of } \\
\text { isolates }\end{array}$ \\
\hline 1 & Alternaria alternata & Solanum tuberosum & 165 \\
\hline 2 & Alternaria alternata & Medicago sativa & 2 \\
\hline 3 & Alternaria alternata & Prunus persica & 2 \\
\hline 4 & Alternaria alternata & Cucumis sativus & 3 \\
\hline 5 & Alternaria alternata & Salix sp. & 2 \\
\hline 6 & Alternaria alternata & Rosa sp. & 2 \\
\hline 7 & Alternaria alternata & Rumex alpinus & 3 \\
\hline 8 & Alternaria alternata & Solanum lycopersicum & 3 \\
\hline 9 & Alternaria alternata & Lactuca sativa & 2 \\
\hline 10 & Alternaria alternata & Amarantus albus & 1 \\
\hline 11 & Alternaria alternata & Acroptilon repens & 2 \\
\hline 12 & Alternaria alternata & Prunus domestica & 3 \\
\hline 13 & Alternaria alternata & Juglans regia & 4 \\
\hline 14 & Alternaria alternata & Althaea officinalis & 2 \\
\hline 15 & Alternaria alternata & Lepidium draba & 2 \\
\hline 16 & Alternaria alternata & Fraxinus excelsior & 3 \\
\hline 17 & Alternaria alternata & Triticum aestivum & 3 \\
\hline 18 & Alternaria alternata & Diospyros sp. & 3 \\
\hline 19 & Alternaria arborescens & Solanum tuberosum & 8 \\
\hline 20 & Alternaria arborescens & Juglans regia & 3 \\
\hline 21 & Alternaria arborescens & Lactuca sativa & 3 \\
\hline 22 & Alternaria arborescens & Solanum lycopersicum & 6 \\
\hline 23 & Alternaria arborescens & Lepidium draba & 2 \\
\hline 24 & Alternaria arborescens & Triticum aestivum & 2 \\
\hline 25 & Alternaria arborescens & Carex sp. & 2 \\
\hline 26 & Alternaria arborescens & Althaea officinalis & 2 \\
\hline 27 & Alternaria dumosa & Solanum tuberosum & 8 \\
\hline 28 & Alternaria dumosa & Althaea officinalis & 2 \\
\hline 29 & Alternaria infectoria & Solanum tuberosum & 3 \\
\hline 30 & Alternaria infectoria & Althaea officinalis & 1 \\
\hline 31 & Alternaria rosae & Alisma plantago & 2 \\
\hline 32 & Alternaria solani & Solanum tuberosum & 15 \\
\hline 33 & Alternaria tenuissima & Malus domestica & 2 \\
\hline 34 & Alternaria tenuissima & Medicago sativa & 3 \\
\hline 35 & Alternaria tenuissima & Fragaria ananassa & 24 \\
\hline 36 & Alternaria tenuissima & Solanum tuberosum & 5 \\
\hline
\end{tabular}

Table 4: List of hosts of Alternaria spp. isolates. 
Citation: Bagherabadi S, Zafari D, Soleimani MJ (2015) Genetic diversity of Alternaria alternata Isolates Causing Potato Brown Leaf Spot, Using ISSR Markers in Iran. J Plant Pathol Microb 6: 286. doi:10.4172/2157-7471.1000286

\begin{tabular}{|c|c|c|c|c|c|}
\hline Item & $\begin{array}{c}\text { Number of } \\
\text { isolates }\end{array}$ & Name of fungus & Host & Cultivar & Region \\
\hline 1 & 16 & Alternaria alternata & Potato & Esprit & Asadabad \\
\hline 2 & 218 & A. alternata & Potato & Sante & Asadabad \\
\hline 3 & 15 & A. alternata & Potato & Marfona & Hamedan \\
\hline 4 & 226 & A. alternata & Potato & Sante & Hamedan \\
\hline 5 & 223 & A. alternata & Potato & Agria & Nahavand \\
\hline 6 & 215 & A. alternata & Potato & Agria & Qorveh \\
\hline 7 & 214 & A. alternata & Potato & Agria & Gahavand \\
\hline 8 & 120 & A. alternata & Potato & Agria & Bahar \\
\hline 9 & 91 & A. alternata & Potato & Agria & Gheidar \\
\hline 10 & 269 & A. alternata & Potato & Agria & Kabodrahng \\
\hline 11 & 286 & A. alternata & Potato & Agria & Razan \\
\hline
\end{tabular}

Table 5: List of the used isolates to determine the genetic diversity of along with the host, cultivars and sample locations.

\section{Pathogenicity test}

After three weeks the symptoms of the disease caused by the 214, 269 and 286 isolates were observed on tested plants. Samples were taken from diseased plant and cultured on PDA and again after ten days of incubation, the pathogen resembles to those of the original isolates, A. alternata was identified. However, no symptoms were observed in other tested isolates.

\section{Results of molecular studies}

Blast search from the gpd gene sequences showed $99 \%$ similarity between representative and A. alternata in the gene bank (Accesion number: KP057228) that confirmed the morphological identification results. The results of molecular studies to determine the genetic diversity of A. alternata isolates using ISSR markers showed that theses markers are excellent choices for fingerprinting genomes of these fungi. Among 15 primers used in this study that they have been selected accroding thier good resultes in previous studies by reseachers, 10 primers did not have favorable results for genotyping in this study, therefore remaining 5 primers were used to study the genetic relationships of this species. Based on the results obtained from these tests, the binding temperature of the primer in most cases, were close to their melting temperature (Table 6).

In this study, ISSR primers, fragments with sizes of 100 to 3000 bp were amplified. Totally, ISSR primers showed 540 bands that 408 bands were polymorphic. The results showed that UBC 807 primer with 157 bands had the highest number of bands and UBC809 primer with 77 bands had the lowest bands. According to the (Figures 1 and 2), UBC809 primer had the highest polymorphism (92\%) and UBC807 primer had the lowest levels of polymorphism (75\%). Finally, 78 bands loci were amplified by ISSR primers that 63 loci of them were polymorphic. In this study we have examined the same ISSR primers which Kale et al. [16] were used in their conducted research, in order to study the genetic diversity of $A$. alternata isolates in linseed. In the study of Kale et al. [16] mean percentage of polymorphic was $98 \%$, whereas in this study, ISSR markers showed $83.3 \%$ polymorphic. The details of used primers in this study are listed in Tables 7 and 8.

\section{Cluster analysis based on ISSR markers}

Comparative analysis of molecular variance showed that the highest difference between the two groups at the cutting point of two groups was obtained at similarity level of $55 \%$, indicating the genetic diversity among $A$. alternata isolates. Isolates regarding to their collected regions were placed in two groups. Isolates collected from Asadabad (Esprit $c v$ ), Hamadan (Marfona $c v$ ), Asadabad (Sante cv), Hamadan (Sante $c v$ ),
Qorveh (Agria $c v$ ), Gheidar (Agria $c v$ ) and Nahavand (Agria $c v$ ) in a separate group and isolates collected from Ghahavand (Agria), Razan (Agria) and Kabodrahng (Agria) were placed in another group.

\begin{tabular}{|c|c|c|}
\hline Primer name & Primer Binding Temperature (Ta) & $\begin{array}{c}\text { Primer Melting } \\
\text { Temperature (Tm) }\end{array}$ \\
\hline UBC807 & 45 & 43 \\
\hline UBC809 & 44 & 44 \\
\hline UBC834 & 48 & 47 \\
\hline UBC835 & 48 & 48 \\
\hline UBC842 & 44 & 44 \\
\hline gpd1, gpd2 & 55 & 58 \\
\hline
\end{tabular}

Table 6: The name of primer, melting temperature and binding temperature of effective specific primers.

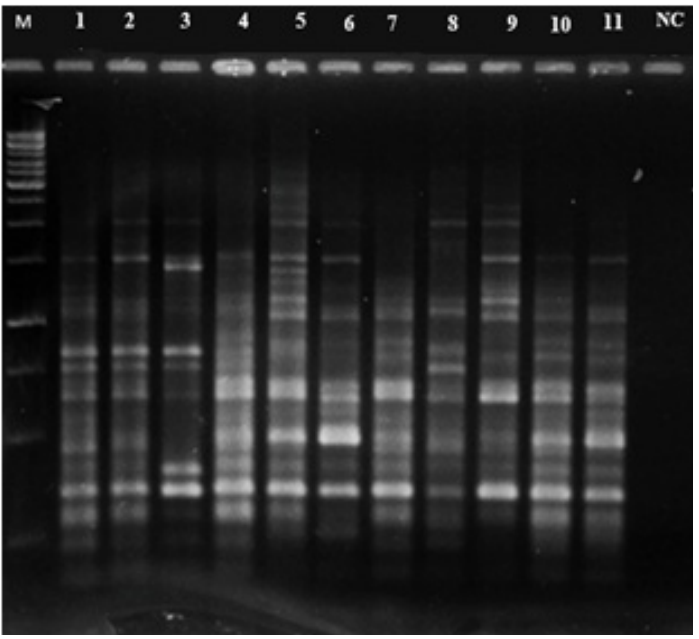

Figure 1: The banding pattern of UBC807 primer application. Molecular marker $1 \mathrm{~Kb} .1$ : Isolates No. 16, 2: Isolates No. 218, 3: Isolates No. 159, 4: Isolates No. 226, 5: Isolates No.223, 6: Isolates No. 215, 7: Isolates No. 214 8: Isolates No. 120, 9: Isolates No. 91, 10: Isolates No.269, 11: Isolates No. 286, NC: Negative Control.

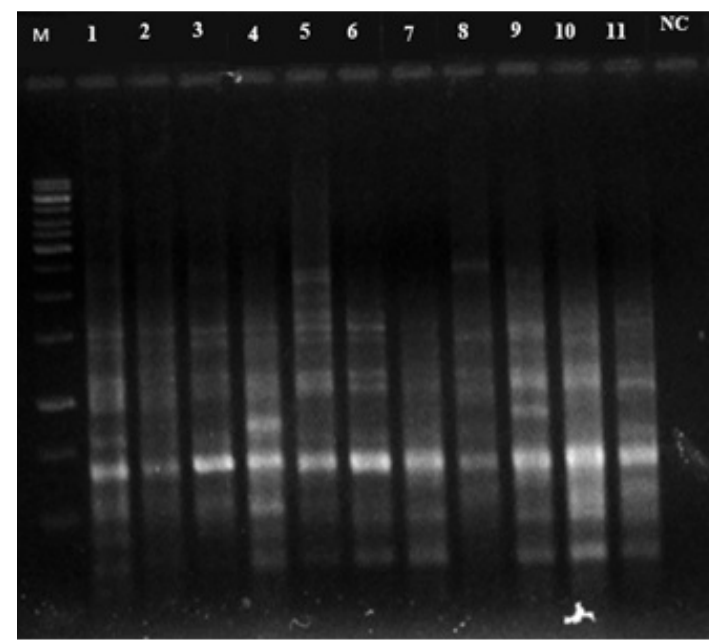

Figure 2: The banding pattern of UBC809 primer application. Molecular marker $1 \mathrm{~Kb} .1$ : Isolates No. 16, 2: Isolates No. 218, 3: Isolates No. 159, 4: Isolates No. 226, 5: Isolates No.223, 6: Isolates No. 215, 7: Isolates No. 214. 8: Isolates No. 120, 9: Isolates No. 91, 10: Isolates No.269, 11: Isolates No. 286, NC: Negative Control. 
The results also showed that isolates of A. alternata on potato had interaspecific variation which indicates that this marker could demonstrate the genetic diversity of this species. The results of cluster analysis showed that in the first group isolates with different cultivars and geographically dispersed areas and non-pathogenic were placed and in second group same cultivar and geographic region close to each other and pathogenic were placed, thus it can be said that there is some correlation between the genetic diversity of this species, geographical distribution, pathogenicity of potato variation. So this might be concluded that isolates from the same locations showed a tendency to group together compared to geographically farther ones. As can be seen in the dendrogram (Figure 3) isolates obtained from Razan, Kabodrahng and Ghahavand with Agria cultivar and pathogenicity in the north part of Hamedan Province placed in one group and the

\begin{tabular}{|c|c|c|c|c|}
\hline $\begin{array}{c}\text { Primer } \\
\text { name }\end{array}$ & $\begin{array}{c}\text { Number of } \\
\text { band loci }\end{array}$ & $\begin{array}{c}\text { Number of } \\
\text { polymorphic loci }\end{array}$ & $\begin{array}{c}\text { Total } \\
\text { number of } \\
\text { loci }\end{array}$ & $\begin{array}{c}\text { Number of } \\
\text { polymorphic bands }\end{array}$ \\
\hline UBC807 & 20 & 15 & 157 & 102 \\
\hline UBC809 & 13 & 12 & 77 & 66 \\
\hline UBC834 & 17 & 14 & 120 & 87 \\
\hline UBC835 & 15 & 13 & 104 & 82 \\
\hline UBC842 & 13 & 11 & 82 & 60 \\
\hline
\end{tabular}

Table 7: Data on locations of bands, polymorphic loci, total bands and polymorphic bands per each primer.

\begin{tabular}{|c|c|}
\hline Studied Parameters & Results \\
\hline Total number of bands & 540 \\
\hline amplified polymorphic bands & 408 \\
\hline number of amplified loci & 78 \\
\hline The number of amplified loci that were polymorphic & 65 \\
\hline The number of amplified loci that were not polymorphic & 13 \\
\hline Percentage of polymorphic & $\% 83 / 3$ \\
\hline The highest percentage of polymorphic & $\% 92($ UBC809) \\
\hline The lowest percentage of polymorphic & $\% 75($ UBC807) \\
\hline The highest number of bands & UBC807))157 \\
\hline The lowest number of bands & UBC809)) 77 \\
\hline The range of band & $100-3000 \mathrm{bp}$ \\
\hline
\end{tabular}

Table 8: The summery of the results obtained for primer used in this study.

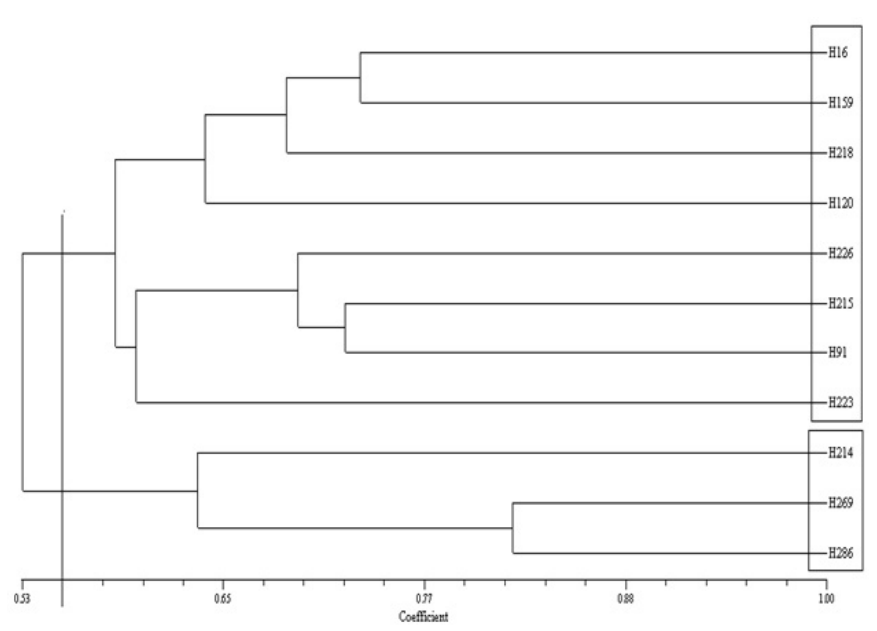

Figure 3: Dendrogram of total ISSR primers used in this study based on Jaccard's similarity coefficient and UPGMA cluster analysis.

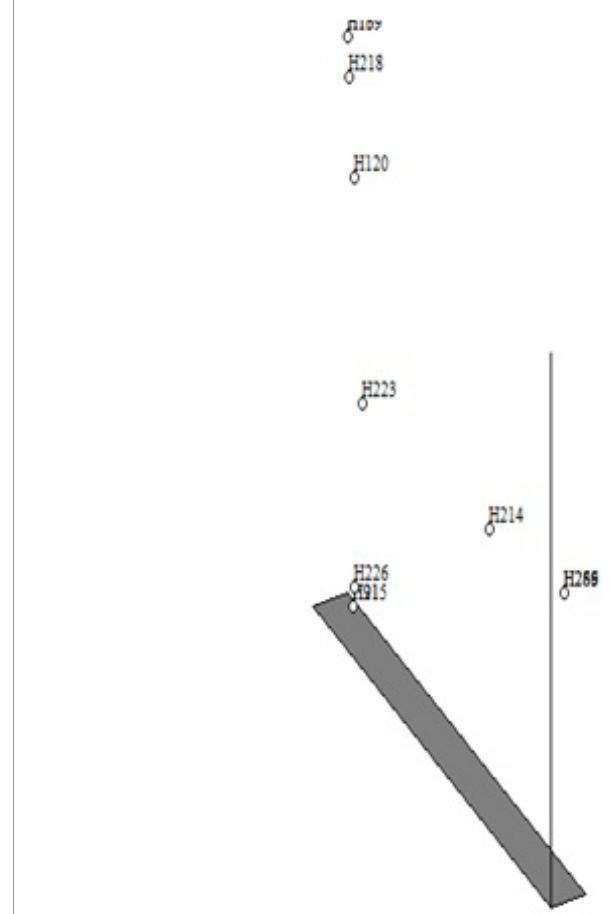

Figure 4: Three-dimensional plot of dialysis to main coordinates using Jaccard's similarity matrix.

remaining isolates on different cultivars and non-pathogenic obtained from other areas of the Hamadan province placed in another group.

Dialysis to main components partially confirmed the cluster analysis results. The first two components justified $70 \%$ of the changes that indicates favorable sampling of these remarks from the whole genome. Thus, each of the markers used in different parts of the genome had less correlation. This method also segregated some isolates from each other in different geographical areas (Figure 4).

This study demonstrated the existence of a narrow range of genetic diversity among potato isolates of A. alternata from Hamedan province, Iran. The isolates had mixed response for cultivars and pathogenicity characteri.

\section{References}

1. Krawczac M, Schmidtke J (1994) DNA fingerprinting. Bioss Scientific Publisher, First ed.

2. Chen JM, Gituru WR, Wang YH, Wang QF (2006) The extent of clonality and genetic diversity in the rare Caldesia grandis (Alismataceae): comparative results for RAPD and ISSR markers. Aguatic Botany 84: 301-307.

3. Simmons EG (1978) Alternaria - an exercise in diversity. Taxonomy of fung (Subramanian CV). University of Madras, Madras, India 1: 130-135.

4. Tokumasu S, Aoiki T (2002) A new approach to studying microfungal succession on decaying pine needles in an oceanic subtropical region in Japan. Fungal Diversity 10: 167-183.

5. Thomma BP (2003) Alternaria spp.: from general saprophyte to specific parasite. Mol Plant Pathol 4: 225-236.

6. Cetano Analles G, Gresshof PM (1997) DNA Markers, Protocoles, Application and owerviews. New York: John Wiley \& Sons.

7. Müller-Starck G, Baradat P, Bergmann F (1992) Genetic variation within European tree species. New Forests 6: 23-47.

8. Ayla FJ, Kiger JA (1984) Modern genetics. (2nded) California USA: Benjamin/ Cummings, Menlo Park. 
Citation: Bagherabadi S, Zafari D, Soleimani MJ (2015) Genetic diversity of Alternaria alternata Isolates Causing Potato Brown Leaf Spot, Using ISSR Markers in Iran. J Plant Pathol Microb 6: 286. doi:10.4172/2157-7471.1000286

Page 6 of 6

9. Beiki AH, Abbaspour N, Mozafari J (2013) Genetic Diversity of Cultivated and Wild Crocus genus in Iran with ISSR Markers. Iranian Journal of Biology 26: 164-173.

10. Gupta PK, Varshney RK (2000) The development and use of microsatellite markers for genetic analysis and plant breeding with emphasis on bread wheat. Euphytica 113: 163-185.

11. Han YC, Teng CZ, Zhong S (2007) Genetic variation and clonal diversity in population of Nelumbo nucifera (Neloumbonaceae) in central China detected by ISSR markers. Aguatic Botany 86: $67-75$

12. Zietkiewicz E, Rafalski A, Labuda D (1994) Genome fingerprinting by simple sequence repeat (SSR)-anchored polymerase chain reaction amplification. Genomics 20: 176-183.

13. Simmons EG (2002) Alternaria themes and variations (305-309) Lewia/ Alternaria revisited. Mycotaxon 83: 127-145.

14. Guo LD, Xu L, Zheng WH, Hyde KD (2004) Genetic variation of Alternaria alternata, an endophytic fungus isolated from Pinus tabulaeformis as determined by random amplified microsatellites (RAMS). Fungal Diversity16: 53-65.

15. Zhong-hui H, Li-hua Z, Lian-chun W, Bao-hua K, Jing-hue F, Hai-ru C, et al. (2011) Optimization of ISSR-PCR Reaction System for Alternaria alternate in Tobacco. Journal of Yunnan Agricultural Unversity 5: 602-606.

16. Kale SM, Pardesh VC, Gurjar GS, Gupta VS, Gohokar RT, et al. (2012) Intersimple sequence repeat markers reveal high genetic diversity among Alternaria alternata isolates of Indian origin. Journal of Mycology and Plant Pathology 42 : 194-200.

17. Barnett HL, Hunter BB (1998) Illustrated genera of imperfect fungi. 4th ed. USA: St Paul.

18. Simmons EG (1796-2007) Alternaria an identification manual fully illustrated and with catalogue raisonne CBS Biodiversity Series No. 6. Published by Utrecht, The Netherlands. CBS Fungal Biodiversity Centre.

19. Sharma AD, Prabhjot KG, Prabhjot S (2002) DNA isolation from dry and fresh samples of polysaccharide - rich plants. Plant Molecular Biology Reporter 20 : $415 a-415 f$ 